\title{
The future of oats in the food and health continuum
}

\author{
Roger Clemens ${ }^{1 *}$ and B. Jan-Willem van Klinken ${ }^{2}$ \\ ${ }^{1}$ School of Pharmacy, International Center for Regulatory Science, University of Southern California, 1540 Alcazar Street, \\ CHP 140, Los Angeles, CA 90033, USA \\ ${ }^{2}$ Quaker Oats, Subsidiary of PepsiCo, Inc., Room 220, 617 W Main Street, Barrington, IL 60011, USA \\ (Submitted 7 October 2013 - Final revision received 1 August 2014 - Accepted 6 August 2014)
}

\section{Abstract}

A large body of clinical evidence suggests that the consumption of $3 \mathrm{~g}$ or more per $\mathrm{d}$ of $\beta$-glucan from oats or barley, as part of a diet low in saturated fat and cholesterol, may reduce the risk of CHD. The unique chemical and physical properties of oats and physiological responses to oat consumption contribute to their demonstrated health benefits; other health attributes are still under evaluation. Many of these benefits, such as those associated with a reduced risk of CVD, are codified in health claims by several regulatory agencies, such as the Food and Drug Administration in the USA and the European Food Safety Authority in Europe. Despite these oat-health relationships, an apparent decline in agricultural production, the presence of an array of plant pathogens, and dynamics of climatic conditions may preclude the availability and subsequent consumption of this commodity worldwide. Therefore, it is incumbent on scientists from multiple disciplines to advance research in a spectrum of arenas, including physico-chemical properties of oats, the impact of oats on an array of non-communicable diseases and human microbiome, agricultural practices and environments, and processing technologies that contribute to global food policies.

Key words: Oats: Health: Agriculture: Policies

\section{Oats and health}

A large body of clinical evidence suggests that the consumption of $3 \mathrm{~g}$ or more per $\mathrm{d}$ of $\beta$-glucan from oats or barley, as part of a diet low in saturated fat and cholesterol, may reduce the risk of $\mathrm{CHD}^{(1,2)}$. Examination of these and other grains indicates that oats are a good source of soluble dietary fibre in the form of $\beta$-glucan, a key component responsible for the health benefits of oats. The unique physico-chemical properties of oats, relative to other grains, and physiological responses to oat consumption contribute to their spectrum of demonstrated health benefits and possibly other health attributes still under evaluation. Many of these benefits, such as those associated with a reduced risk of CVD, are codified in health claims by several regulatory agencies, such as the Food and Drug Administration in the USA, and by the European Food Safety Authority in Europe ${ }^{(3,4)}$. Table 1 summarises the key findings from each article in this supplement.

Oats (Avena sativa L.) are a cereal grain commodity well known for their health benefits. Despite this, oat production is declining and the challenges associated are ensuring that the future of oats is little known to the public and scientific community. The world's sequencing databases hold about 80000 accessions of cultivated oat species and preserve about 20000 accessions of wild Avena species ${ }^{(5)}$. Extensive knowledge of this diversity of cultivars is critical to ensuring that oats can be grown in changing environments, for example, with respect to climate change and water availability, and to ensuring resources for crop improvement and promoting the attributes of oats that provide health benefits.

Although the epidemiological data are not compelling, the spectrum of clinical studies supports the health benefits and subsequent health claims. These studies demonstrate the direct relationship between oat consumption and reduced risk of several diseases, including CVD, diabetes and possibly some cancers. Surprisingly, no cohort studies that have evaluated the effects of regular consumption of oats specifically either on CVD or diabetes and few studies that have included cancer as an outcome variable have been identified ${ }^{(6)}$. The results of most of the few cohort studies suggest a weak protective effect of high intake of oats on cancer risk (relative risks in the order of 0.9). Overall, very few epidemiological studies have been performed on the effects of oat consumption: there is an urgent need for such studies. An assessment of a Nordic population with regard to whole-grain or oat consumption relative to overall mortality indicates that oatmeal consumption may improve longevity ${ }^{(7)}$. However, these observations deserve

Abbreviation: MW, molecular weight.

*Corresponding author: R. Clemens, email clemens@usc.edu 
Table 1. Key messages on the value of and research on oats

\begin{tabular}{|c|c|}
\hline Categories & Messages \\
\hline Physical properties & $\begin{array}{l}\text { Physico-chemical properties of oat } \beta \text {-glucan are important for the determination of blood glucose and } \\
\text { cholesterol-lowering efficacy of oats } \\
\text { An increase in digesta viscosity in the gastrointestinal tract caused by oat } \beta \text {-glucan is one of the main determinants } \\
\text { of the positive metabolic effects of oats }\end{array}$ \\
\hline Oats and CVD & $\begin{array}{l}\text { Oat consumption may contribute to a reduced risk of CVD as assessed by typical lipid biomarkers, such as lower } \\
\text { LDL-cholesterol, total cholesterol and TAG levels, and often increased HDL levels } \\
\text { Possible cardiovascular benefits are supported by a qualified health claim in the USA } \\
\text { Most oat consumption intervention studies have not demonstrated a beneficial effect on the biomarkers of diabetes, including } \\
\text { fasting insulin plasma levels, insulin sensitivity and A1C }\end{array}$ \\
\hline $\begin{array}{l}\text { Oats and } \\
\text { bowel disease }\end{array}$ & $\begin{array}{l}\text { Oat consumption contributes to increased stool weight and decreased constipation } \\
\text { Limited evidence from intervention studies suggests that oat consumption may reduce the risk of both bowel } \\
\text { inflammatory disorders (including ulcerative colitis) and colorectal cancer } \\
\text { Appropriately sourced oats may be safely consumed by those with coeliac disease } \\
\text { Oat consumption is not contraindicated among those presenting with bowel disease or those following } \\
\text { a gluten-free dietary regimen } \\
\text { There is some evidence suggesting that oat consumption contributes to increased SCFA production by the gut microflora }\end{array}$ \\
\hline Epidemiology & $\begin{array}{l}\text { Despite the extensive clinical research to date, no epidemiological studies on the effects of oat consumption on the risk of } \\
\text { CVD or diabetes have been identified } \\
\text { There is limited epidemiological evidence supporting a weak association of oat consumption with reduced cancer risk }\end{array}$ \\
\hline Gut health & $\begin{array}{l}\text { The unique composition of oats may provide important fermentable constituents for the gut microflora } \\
\text { Resistant starch in oats favours increased viscosity in the gut, which in turn may favourably affect microflora in the distal colon } \\
\text { of humans, possibly affecting gut hormones }\end{array}$ \\
\hline Agriculture & $\begin{array}{l}\text { Global production of oats, unlike other grains, appears to be declining possibly due to (in the USA) potential climate changes, } \\
\text { emerging plant diseases, and lack of crop subsidy (in the USA) } \\
\text { Alternations in agricultural practices, including fertiliser technologies/techniques and drought/disease-resistant cultivars, may } \\
\text { improve the availability of oats } \\
\text { Oat breeding, employing molecular biology and plant genetics techniques, can improve the quality and quantity of oats, } \\
\text { enhance consumption and hence improve consumers' health }\end{array}$ \\
\hline Processing & $\begin{array}{l}\text { Milling oats improves the nutrient availability of components, such as } \beta \text {-glucan and other forms of fibre, lipids and protein } \\
\text { endogenous to this grain }\end{array}$ \\
\hline Food policy & $\begin{array}{l}\text { Most dietary guidelines encourage an increased consumption of whole grains, including oats } \\
\text { Whole grains, including oats, are codified in a health claim relative to heart disease in the USA } \\
\text { Whole grains, including oats, are central in a qualified health claim relative to type II diabetes in the USA } \\
\text { Similar oat health claims, associated with its } \beta \text {-glucan contribution, are accepted by the European Union and Health Canada }\end{array}$ \\
\hline
\end{tabular}

additional investigation, particularly among various population groups living in other geographical regions.

$\beta$-Glucan, a unique linear carbohydrate in the starchy endosperm that is common to oat grain, is one of the many components that contribute to the health benefits of this cereal. As a form of soluble fibre, the physiological effects on lipid and carbohydrate metabolism may reflect the rheological properties in the gastrointestinal tract ${ }^{(8,9)}$. The concentration of $\beta$-glucan is variable, depending on cultivar, growing conditions and processing conditions, storage and purification protocol. The molecular weight (MW) of $\beta$-glucan is influenced by cultivars and even by the purification technique ${ }^{(10)}$. In fact, the MW and solubility of $\beta$-glucan are critical to the ability to form viscous material that may underlie many of its purported health benefits. In fact, recent clinical studies have shown that satiety ratings are increased significantly up to $4 \mathrm{~h}$ after oatmeal consumption, which is correlated with increased viscosity, content and MW of $\beta$-glucan ${ }^{(11-13)}$. Despite these apparent correlations, in most clinical studies, the MW of $\beta$-glucan was not controlled for or dissimilar methods were used. It is therefore essential that methods be standardised between research laboratories, enabling accurate determination of the MW and viscosity of $\beta$-glucan.
The majority of clinical trials that have assessed the potential health impact of oats indicate that fasting plasma total and LDL-cholesterol, blood pressure and homocysteine levels - all risk factors for CVD - may be significantly reduced. As Thies et $a l^{(2)}$ confirmed in their assessment, long-term dietary intake of oats or oat bran has a beneficial effect on blood cholesterol. In addition, evidence from many studies indicates that fasting blood glucose, a risk factor for CVD and associated with diabetes, remains unchanged (albeit postprandial glycaemia may be reduced), whereas oat consumption does not appear to affect insulin sensitivity ${ }^{(2)}$.

There is a plethora of gut-health pathologies, notably Crohn's disease, coeliac disease, ulcerative colitis, inflammatory bowel disease, irritable bowel syndrome and colorectal cancer. A systematic review of the literature on clinical trials relative to these conditions and oat consumption indicates the absence of any major effect on the course of colorectal cancer, ulcerative colitis (a type of irritable bowel disease) or irritable bowel syndrome ${ }^{(14)}$, although yet to be established benefits may become evident during long-term consumption of oats. Importantly, however, the data indicate that oat consumption was well tolerated by most of the study subjects. Oats significantly increased stool weight and decreased constipation, although 
effects did not seem specific to oats and are general to whole grains $^{(14)}$. Importantly, oat consumption is well tolerated by most coeliac disease patients, and therefore uncontaminated oats may provide an opportunity to consume sufficient whole grains for this population ${ }^{(14)}$. Some of the mechanisms that may improve clinical outcomes were identified in animal models and human studies for these conditions ${ }^{(15,16)}$. However, well-designed clinical studies investigating the impact of longterm oat consumption on bowel disorders are needed.

Our understanding of the role of the gut microbiota in the health and disease spectrum has increased exponentially over recent decades. The impact of whole grains, including oats, and their components (such as resistant starch, $\beta$-glucan, lignins and lipids) may modulate gut microflora, which alters the array of cellular signalling processes that contribute to improved health ${ }^{(17)}$. In vitro and clinical studies indicate that different whole grains, such as oats and barley, have diverse effects on the gut microflora. These effects may reflect unique grain compositions, such as avenanthramides and related substances in oats, that contribute to variations in proximal and distal fermentation products (SCFA), alterations in microenvironment $\mathrm{pH}$, changes in nutrient absorption (decreased cholesterol uptake and increased absorption of some minerals and vitamins), or the synthesis of vitamins (folic acid and vitamin $\mathrm{K}$ ). The potential impact of the gut microbiome on heart health $^{(18)}$, immune function ${ }^{(19)}$, diabetes ${ }^{(20)}$ and obesity ${ }^{(21)}$ provides tremendous opportunities for future applications for oats. In addition, increased production of SCFA is correlated with enhanced satiety ${ }^{(22)}$.

\section{Satiety}

Epidemiological evidence suggests that regular consumption of whole-grain foods, such as oats, is correlated with lower BMI ${ }^{(23)}$. Whole-grain foods are thought to be satiating due to their high fibre content relative to other grains, although a recent systematic review has suggested otherwise ${ }^{(24)}$. As has been mentioned earlier, oats are high in $\beta$-glucan, which is thought to play an essential role in the elicitation of this acute satiety response ${ }^{(25)}$. However, clinical studies with oat-based foods or beverages provide inconsistent results - for example, in a study, consumption of bars containing up to $0.9 \mathrm{~g}$ of $\beta$-glucan from barley was found to not demonstrate enhanced satiety compared with that of an isoenergetic control bar ${ }^{(26)}$. In a study with extruded muesli containing $4 \mathrm{~g}$ of $\beta$-glucan per serving, no differences were found in short-term satiety compared with cornflakes, which are low in fibre ${ }^{(27)}$. Similarly, consumption of bread containing oats or wheat fibre and that of low-fibre control bread were found to not differ in perceived satiety $^{(28)}$.

Studies that investigated oats or $\beta$-glucan in a beverage, soup or cooked oatmeal seem more consistent in their outcomes related to hunger and fullness, i.e. measures of satiety response. These observations suggest that hydration of the oat fibres may be essential for their satiety response. For example, Juvonen et $a l^{(29)}$ found that an isoenergetic oat-bran-based beverage with high viscosity elicited enhanced satiety responses compared with a $\beta$-glucanase-treated low-viscosity oat-bran beverage. Lyly et al. ${ }^{(30)}$ demonstrated enhanced satiety of a $\beta$-glucan-containing beverage compared with fibre-free controls. In a small study with nineteen participants, a trend in reduced hunger ratings was observed after consumption of cooked oatmeal than after the consumption of a soluble-fibre control cereal ${ }^{(31)}$. Also, in a study among school-aged children, a small serving of $43 \mathrm{~g}$ of oatmeal was found to significantly decrease hunger ratings compared with an isoenergetic ready-to-eat cereal ${ }^{(32)}$.

Recently, three independent studies with larger groups of healthy adult volunteers have provided stronger, consistent evidence on the satiating effects of oatmeal. In one study, cooked classic oatmeal (66 g) was compared with isoenergetic ready-to-eat cereal, and visual analogue scale (of hunger) data were obtained from 0 to $240 \mathrm{~min}$ after consumption of the test meal. Results indicated significantly increased satiety from 2 to $4 \mathrm{~h}^{(13)}$. These findings were corroborated in a similarly designed study that compared cooked oatmeal with the same ready-to-eat cereal ${ }^{(12)}$, in which the oatmeal-fed volunteers consumed significantly less of a meal that was offered $4 \mathrm{~h}$ later. Therefore, a composite of these studies indicates that cooked oatmeal delivers satiating benefits, although a large intervention or clinical study is yet to be undertaken.

In an in vitro study using a model that simulated gastric digestion, the underlying viscosity exerted by $\beta$-glucan appeared to be a key factor in this satiating response $v$. that of the starch content of the oatmeal. Furthermore, cooked oatmeal, but not ready-to-eat cereal, exhibited enhanced gastric gelling in the in vitro model, suggesting that this property may contribute to delayed gastric emptying and subsequent enhanced satiety in vivo ${ }^{(11)}$

\section{Agriculture, processing and policy}

Maximisation of the physiological benefits of oat consumption requires better understanding and appreciation of agricultural practices and challenges and processing technologies. The cultivation and production of oats involve understanding phenotypic and genetic variations associated with the climate and climate changes, environmental or abiotic stresses, plant pathogens and diseases, and agricultural production issues, wherever the oat crop is grown ${ }^{(32)}$. Each of these variables affects the composition and nutritive value of the grain. The growing agriculture genebank for oat cultivars indicates that there are still numerous research opportunities to ensure the availability of oats to help meeting the food needs and health demands of a growing global population.

Regardless of the source of the oat grain or kernel, some elements of processing are essential to keep the unique nutritional properties (such as lipids, fibre and $\beta$-glucan) physiologically available ${ }^{(33)}$. For example, the extent of oat milling depends on many variables, such as plant genetics, agricultural practices, chemical composition, storage and handling conditions. Grading oats for quality before milling is critical for their ultimate conversion into an array of wholesome food ingredients and products.

Translation of the basic and applied research to global food policies to address contemporary and future health concerns

\begin{abstract}
satiety responses compared with a $\beta$-glucanase-treated
\end{abstract}


and food supply challenges is essential if oats are to be seen as a priority crop ${ }^{(3)}$. Recent reports from the WHO and FAO indicate a significant intersection between tackling poor nutrition and environmental challenges ${ }^{(35,36)}$. The global double public burden of undernutrition and obesity involves a spectrum of challenges for future health. The future of food and farming requires greater research into global crops, such as oats ${ }^{(37)}$, and the concept of sustainable diets ${ }^{(38)}$ for a healthy future. This research, in turn, drives food policy, health claims and consumer-friendly product labelling, which are intended to improve consumer health outcomes through better consumer education, a broader selection of healthy foods, and improved food supply. Although there are variations in dietary guidelines between countries, there is a common recommendation for consumers to increase their consumption of whole grains, including oats ${ }^{(39)}$. These publications, and health-orientated and socially conscious consumers, can provide a basis for advocating for agricultural policy for crop improvements and stabilised production. These dynamics also drive regulatory policy and future food products based on clinical evidence and consumer opinion. Current and future agricultural and nutrition policies provide synergistic opportunities that support sustainable agriculture and improved public health.

\section{Conclusion}

Oats are cereal grains that are commonly accepted by consumers globally. They appear in a wide range of food products, including low-energy beverages, medical foods, baked goods and granolas. In a time of increasing global food-security issues and dual health burdens of overweight and underweight, oats could be part of inexpensive, nutritious products for the future.

Global dietary guidelines recommend an increased consumption of whole grains for improved health. Oats are a unique type of beneficial whole grains and should be promoted for their evidence-based impact on the risk of CVD and, if the evidence bears out, potentially gut health and some forms of cancers. Effects of acute consumption of oats on satiety and glucose management are more evident in contrast to those of long-term consumption. These arena areas are crucial basic and applied research opportunities in human health and nutrition. The wide-ranging benefits of oats justify the expansion of agricultural practices and cultivar assessments intended to sustain oats in stress-laden environments and in the face of common pathogens and to explore processing technologies that ensure that the nutritional qualities and health attributes of oats are maintained and that oats, a global commodity, remain available to a growing population.

\section{Acknowledgements}

R. C. received an honorarium from Quaker Oats Company (a subsidiary of PepsiCo, Inc.) for attending the workshop in May 2012 to discuss the content of the supplement and to function as managing editor of the series of manuscripts. B. J.-W. v. K. is an employee of PepsiCo, Inc. The views expressed in this article are those of the author(s) and do not necessarily reflect the position or policy of PepsiCo, Inc. This article was jointly authored by R. C. and B. J.-W. v. K.

This paper was published as part of a supplement to British Journal of Nutrition, publication of which was supported by an unrestricted educational grant from Quaker Oats Co. (a subsidiary of PepsiCo Inc.). The papers included in this supplement were invited by the Guest Editor and have undergone the standard journal formal review process. They may be cited.

The Guest Editor to this supplement is Roger Clemens. The Guest Editor declares no conflict of interest.

\section{References}

1. FDA (2012) Code of Federal Regulations (Title 21, Section 101.81).

2. Thies F, Masson LF, Boffetta P, et al. (2014) Oats and CVD risk markers: a systematic literature review. Br J Nutr 112, S19-S30.

3. Stewart D, Kennedy A \& Pavel A (2014) Beyond nutrition and agriculture policy: collaborating for a food policy. Br J Nutr 112, S65-S74.

4. EFSA (2011) Panel on Dietetic Products, Nutrition and Allergies (NDA); Scientific Opinion on the substantiation of health claims related to beta-glucans from oats and barley and maintenance of normal blood LDL-cholesterol concentrations (ID1236, 1299), increase in satiety leading to a reduction in energy intake (ID 851, 852), reduction of post-prandial glycaemic responses (ID 821, 824), and "digestive function" (ID 850) pursuant to Article 12(1) of Regulation (EC) No 1924/2066. EFSA Journal 9, 2207. [21 pp].

5. Badaeva ED, Shelukhina OY, Diederichsen A, et al. (2010) Comparative cytogenic analysis of Avena macrostachya and diploid C-genome Avena species. Genome 53, 125-137.

6. Boffetta P, Thies F \& Kris-Etherton P (2014) Epidemiological studies of oat consumption and risk of cancer and overall mortality. Br J Nutr 112, S14-S18.

7. Olsen A, Egebert R, Halkjær J, et al. (2011) Healthy aspects of the Nordic diet are related to lower total mortality. J Nutr 141, 639-644.

8. Wolever TMS, Tosh SM, Gibbs AL, et al. (2010) Physiochemical properties of oat $\beta$-glucan influence its ability to reduce serum LDL cholesterol in humans: a randomized clinical trial. Am J Clin Nutr 92, 723-732.

9. Tosh SM (2013) Review of human studies investigating the post-prandial blood-glucose lowering ability of oat and barley food products. Eur J Clin Nutr 67, 310-317.

10. Wang Q \& Ellis PR (2014) Oat $\beta$-glucan: physico-chemical characteristics in relation to its blood glucose and cholesterol-lowering properties. Br J Nutr 112, S4-S13.

11. van Klinken BJ-W, Chu Y, Bordenave N, et al. (2013) Predicting satiety responses of cereals in vitro: oatmeal shows gastric gelling behavior. FASEB J 27, 126.5 (abstract).

12. Rebello CJ, Johnson W, Martin C, et al. (2013) Effect of two oat-based breakfast cereals on appetite, satiety, and food intake. FASEB J 27, 126.4 (abstract).

13. Rebello CJ, Johnson WD, O'Shea M, et al. (2012) Effect of breakfast cereals with varying doses of oat fiber on appetite and satiety. FASEB J 26, 363.3 (abstract).

14. Thies F, Masson LF, Boffetta P, et al. (2014) Oats and bowel disease: a systematic literature review. Br J Nutr 112, S31-S43. 
15. Sengupta S, Muir JG \& Gibson PR (2006) Does butyrate protect from colorectal cancer? J Gastroenterol Hepatol 21, 209-218.

16. Slavin JL, Martini MC, Jacobs DR Jr, et al. (1999) Plausible mechanisms for the protectiveness of whole grains. Am J Clin Nutr 70, Suppl., 459S-463S.

17. Rose DJ (2014) Impact of whole grains on the gut microbiota: the next frontier for oats? Br J Nutr 112, S44-S49.

18. Wong JM, Esfahani A, Singh N, et al. (2012) Gut microbiota, diet and heart disease. J AOAC Int 95, 24-30.

19. Purchiaroni F, Tortora A, Gabrielli M, et al. (2013) The role of intestinal microbiota and the immune system. Eur Rev Med Pharmacol Sci 17, 323-333.

20. Cani PD, Osto M, Geurts L, et al. (2012) Involvement of gut microbiota in the development of low-grade inflammation and type 2 diabetes associated with obesity. Gut Microbes 3, 279-288.

21. Arora T \& Sharma R (2011) Fermentation potential of the gut microbiome: implications for energy homeostasis and weight management. Nutr Rev 69, 99-106.

22. Darzi J, Frost GS \& Robertson MD (2011) Do SCFA have a role in appetite regulation? Proc Nutr Soc 70, 119-128.

23. Giacco R, Della Pepa G, Luongo E, et al. (2011) Whole grain intake in relation to body weight: from epidemiological evidence to clinical trials. Nutr Metab Cardiovasc Dis 21, 901-908.

24. Clark MJ \& Slavin JL (2013) The effect of fiber on satiety and food intake: a systematic review. J Am Coll Nutr 32, 200-211.

25. Lyly M, Liukkonen KH, Salmenkallio-Marttila M, et al. (2009) Fibre in beverages can enhance perceived satiety. Eur J Nutr 48, 251-258.

26. Peters HP, Boers HM, Haddeman E, et al. (2009) No effect of added $\beta$-glucan or of fructooligosaccharide on appetite or energy intake. Am J Clin Nutr 89, 58-63.

27. Hlebowicz J, Darwiche G, Björgell O, et al. (2008) Effect of muesli with $4 \mathrm{~g}$ oat $\beta$-glucan on postprandial blood glucose, gastric emptying and satiety in healthy subjects: a randomized crossover trial. J Am Coll Nutr 27, 470-475.
28. Weickert MO, Spranger J, Holst JJ, et al. (2006) Wheat-fibreinduced changes of postprandial peptide YY and ghrelin responses are not associated with acute alterations of satiety. Br J Nutr 96, 795-798.

29. Juvonen KR, Purhonen AK, Salomenkallio-Marttila M, et al. (2009) Viscosity of oat bran-enriched beverages influences gastrointestinal hormonal responses in healthy humans. J Nutr 139, 461-466.

30. Lyly M, Ohls N, Lahteenmaki L, et al. (2010) The effect of fibre amount, energy level and viscosity of beverages containing oat fibre supplement on perceived satiety. Food Nutr Res 54, 2149.

31. Saltzman E, Moriguti JC, Das SK, et al. (2001) Effects of a cereal rich in soluble fiber on body composition and dietary compliance during consumption on a hypocaloric diet. $J \mathrm{Am}$ Coll Nutr 20, 50-57.

32. Mahoney CR, Taylor HA, Kanarek RB, et al. (2005) Effect of breakfast composition on cognitive processes in elementary school children. Physiol Behav 85, 635-645.

33. Stewart D \& McDougall G (2014) Oat agriculture, cultivation and breeding targets: implications for human nutrition and health. Br J Nutr 112, S50-S57.

34. Decker EA, Rose D \& Stewart D (2014) Processing of oats and the impact of processing operations on nutrition and health benefits. Br J Nutr 112, S58-S64.

35. World Health Organization (2013) Global Nutrition Policy Review: What Does it Take to Scale Up Nutrition Action? Geneva: World Health Organization.

36. UN Food and Agriculture Organization (2013) The State of Food and Agriculture. Rome: UN FAO.

37. Government Office for Science (2011) Foresight: The Future of Food and Farming: Challenges and Choices for Global Sustainability. London: Government Office for Science.

38. Food and Agriculture Organization (2010) Sustainable Diets and Biodiversity: Directions and Solutions for Policy, Research and Action. Rome: FAO.

39. Painter J, Rah J-H \& Lee Y-K (2002) Comparison of international food guide pictorial representations. J Am Diet Assoc 102, 483-489. 